\title{
Balloon dilatation of unoperated aortic coarctation: immediate results and one year follow up
}

\author{
CHRISTOPHER WREN, IAN PEART, HUGH BAIN, STEWART HUNTER \\ From the Department of Paediatric Cardiology, Freeman Hospital, Newcastle upon Tyne
}

SUMMARY Fifteen patients aged 1-19 years (mean 10.9) with previously unoperated aortic coarctation underwent percutaneous balloon angioplasty between January 1985 and February 1986. Nine $(60 \%)$ were hypertensive at presentation. Under general anaesthetic the systolic coarctation gradient was 24-50 mm Hg (mean 29) and the coarctation diameter was 4-9 mm (mean 5.5). Meditech balloon catheters 8-18 mm in diameter were inflated 1-4 times at $410-760 \mathrm{kPa}$. After dilatation the systolic coarctation gradient decreased to $0-20 \mathrm{~mm} \mathrm{Hg}$ (mean 6) and the coarctation diameter increased to $7-20 \mathrm{~mm}$ (mean 12). One patient developed a fusiform aneurysm of the aorta at the coarctation site immediately after the procedure. At reinvestigation 6-16 months (mean 12.5) after dilatation 14 of the 15 patients were normotensive. In 13 patients the residual coarctation gradient was $0-10 \mathrm{~mm} \mathrm{Hg}$ (mean 3). Two patients had recoarctation with residual gradients of 20 and $24 \mathrm{~mm} \mathrm{Hg}$ and underwent successful repeat dilatation. One patient had developed a small discrete aneurysm at the coarctation site.

Balloon angioplasty is thus a safe and effective method of relieving unoperated aortic coarctation. The frequency of aortic aneurysm and recoarctation is small and probably related to balloon size. This early experience is encouraging, but long term results and further experience are required before this approach is used to treat coarctation generally.

Surgical treatment has greatly improved the long term prognosis in patients with coarctation of the aorta. However, while operation may repair the aorta, long term follow up studies indicate that it does not cure the patient. ${ }^{1}$

Relief of coarctation by balloon angioplasty is now feasible ${ }^{2-4}$ and, in view of the higher operative morbidity and mortality associated with reoperation, has been proposed as the first line treatment of postoperative restenosis of coarctation. ${ }^{5}$ Vascular complications and the transient benefit from angioplasty have limited the use of this technique in infancy. ${ }^{6}$

Balloon angioplasty achieves its effect by disrupting the intima and media at the site of the coarctation. ${ }^{78}$ Concern over the possibility of late aneurysm formation at the site of dilatation ${ }^{910}$ has also restricted the adoption of the technique for relief of unoperated coarctation after infancy.

Requests for reprints to Dr Christopher Wren, Ward 23, Freeman Hospital, Newcastle upon Tyne NE7 7DN.

Accepted for publication 6 July 1987
This report presents the immediate results of balloon angioplasty in a consecutive group of patients over 12 months of age and the results of reinvestigation one year later.

\section{Patients and methods}

PATIENTS

Between January 1985 and February 198618 patients over the age of 12 months presented to this hospital with unoperated coarctation of the aorta (table). Two patients with associated ductus arteriosus and another with virtual atresia of the aorta were considered unsuitable for angioplasty and were referred for surgery. The remaining 15 patients underwent balloon angioplasty. Their ages ranged from 1 to 19 years (mean 10.9 years). Three patients had associated abnormalities (one had Beckwith's syndrome, one had moderate mitral regurgitation, and the third had moderate aortic valve stenosis).

All patients underwent repeat cardiac catheterisation at 6-16 months (mean 12.5 months) after the initial procedure. 
Table Details of patients and procedures

\begin{tabular}{|c|c|c|c|c|c|c|c|c|c|}
\hline Patient & $\begin{array}{l}\text { Age } \\
(y r)\end{array}$ & $\begin{array}{l}\text { Weight } \\
(\mathrm{kg})\end{array}$ & $\begin{array}{l}\text { Initial } B P \\
(m m H g)\end{array}$ & $\begin{array}{l}C O A \\
\text { gradient } \\
(\mathrm{mm} \mathrm{Hg})\end{array}$ & $\begin{array}{l}C O A \\
\text { diameter } \\
(\mathrm{mm})\end{array}$ & $\begin{array}{l}\text { Balloon } \\
\text { size } \\
(\mathrm{mm})\end{array}$ & $\begin{array}{l}\text { Balloon: } \\
\text { COA } \\
\text { ratio }\end{array}$ & $\begin{array}{l}F / U B P \\
(m m H g)\end{array}$ & Comments \\
\hline $\begin{array}{r}1 \\
2 \\
3 \\
4 \\
5 \\
6 \\
7 \\
8 \\
9 \\
10 \\
11 \\
12 \\
13 \\
14 \\
15\end{array}$ & $\begin{array}{r}10 \\
1 \\
8 \\
11 \\
5 \\
10 \\
10 \\
17 \\
14 \\
17 \\
18 \\
19 \\
6 \\
2 \\
15\end{array}$ & $\begin{array}{r}33 \\
8 \\
29 \\
38 \\
19 \\
27 \\
30 \\
55 \\
59 \\
72 \\
69 \\
52 \\
26 \\
12 \\
58\end{array}$ & $\begin{array}{l}145 / 105 \\
145 / 80 \\
120 / 60 \\
145 / 85 \\
105 / 80 \\
110 / 60 \\
140 / 70 \\
170 / 105 \\
125 / 80 \\
170 / 90 \\
170 / 70 \\
170 / 90 \\
116 / 76 \\
120 / 60 \\
170 / 105\end{array}$ & $\begin{array}{l}30 \\
24 \\
31 \\
50 \\
26 \\
30 \\
30 \\
30 \\
32 \\
30 \\
24 \\
22 \\
26 \\
24 \\
26\end{array}$ & $\begin{array}{l}4 \\
4 \\
5 \\
4 \\
6 \\
6 \\
5 \\
4 \\
7 \\
8 \\
9 \\
7 \\
4 \\
5 \\
4\end{array}$ & $\begin{array}{l}18 \\
15 \\
12 \\
15 \\
12 \\
12 \\
12 \\
15 \\
15 \\
18 \\
18 \\
15 \\
10 \\
10 \\
15\end{array}$ & $\begin{array}{l}4 \cdot 5 \\
3 \cdot 8 \\
2 \cdot 4 \\
3 \cdot 8 \\
2 \cdot 0 \\
2 \cdot 0 \\
2 \cdot 4 \\
3 \cdot 8 \\
2 \cdot 1 \\
2 \cdot 3 \\
2 \cdot 0 \\
2 \cdot 1 \\
2 \cdot 5 \\
2 \cdot 0 \\
3 \cdot 8\end{array}$ & $\begin{array}{r}95 / 80 \\
110 / 70 \\
120 / 70 \\
115 / 80 \\
105 / 70 \\
110 / 60 \\
120 / 80 \\
120 / 70 \\
130 / 80 \\
150 / 60 \\
110 / 70 \\
120 / 80 \\
110 / 60 \\
110 / 70 \\
120 / 80\end{array}$ & $\begin{array}{l}\text { Small aneurysm at } 12 \text { months } \\
\text { Immediate fusiform aneurysm }\end{array}$ \\
\hline
\end{tabular}

BP, blood pressure; COA, coarctation; balloon:COA, ratio of balloon diameter to coarctation diameter; F/U BP, blood pressure on admission for repeat cardiac catheterisation.

\section{METHODS}

Informed consent to balloon angioplasty was obtained before investigation in all patients, and all procedures were performed under general anaesthesia. The balloon dilatation was performed during the initial catheterisation in 12 patients. The other three patients had been catheterised before. Catheters were introduced percutaneously via the femoral artery. Initial assessment included simultaneous measurement of pressure in the ascending aorta and femoral artery, measurement of withdrawal pressure across the site of coarctation, and a cineaortogram in the left anterior oblique projection. The diameter of the aorta above the coarctation was measured from a freeze frame image on a video monitor with correction for magnification from the known diameter of the cardiac catheter. A balloon size that was 1 to $2 \mathrm{~mm}$ smaller than the aortic diameter was chosen. The balloon catheters (Meditech) were introduced percutaneously without an arterial sheath and were advanced to the site of the coarctation over a guide wire. Dilute radiographic contrast medium was used for balloon inflation, with accurate positioning of the balloon being assessed by the appearance of a waist at the site of coarctation. The balloon was inflated at pressures between $410-760 \mathrm{kPa}$. If waisting was not produced the position of the balloon was adjusted and the procedure was repeated. No patient had more than four balloon inflations. The duration of inflation varied but did not exceed 15 seconds.

After deflation the balloon catheter was withdrawn but the guide wire was left in place across the coarctation site. An end-hole catheter was positioned in the aortic arch for repeat simultaneous measurement of pressure in the ascending aorta and femoral artery and angiography. After the procedure haemostasis was achieved by femoral artery com- pression. Patients were monitored closely in the recovery period, with particular attention being paid to the peripheral pulses and blood pressure, and all had a postoperative chest $x$ ray to detect mediastinal widening. Patients rested in bed for 24 hours and were allowed home on the second postoperative day. All were prescribed oral atenolol for one month.

During the course of the study certain modifications were made to the above procedure. Patients 1-3 were not heparinised during the dilatation procedure because of the possible risk of intramural haemorrhage after angioplasty. As this did not prove to be a problem we felt that the risk of embolism related to the prolonged use of guide wires during the procedure was greater and so patients 4-15 were anticoagulated with 100 units $/ \mathrm{kg}$ of sodium heparin before the introduction of the guide wire. Pressure recordings from the right radial and the contralateral femoral artery are now monitored throughout the procedure so that the residual gradient can be measured without withdrawing the balloon catheter completely, thereby avoiding unnecessary trauma to the femoral artery.

Results were compared by Student's paired $t$ test as appropriate.

\section{Results}

Nine $(60 \%)$ of the 15 patients were hypertensive on presentation (table). Under general anaesthesia the pressure gradient across the coarctation ranged from 24 to $50 \mathrm{~mm} \mathrm{Hg}$ (mean $29 \mathrm{~mm} \mathrm{Hg}$ ) (fig 1). The diameter of the aorta immediately above the coarctation ranged from 6 to $23 \mathrm{~mm}$ and at the coarctation from 4 to $9 \mathrm{~mm}$ (mean $5.5 \mathrm{~mm}$ ) (fig 2). These measurements were taken from cineangiograms developed after the procedure. The balloon catheters used for dilatation were between 8 and 


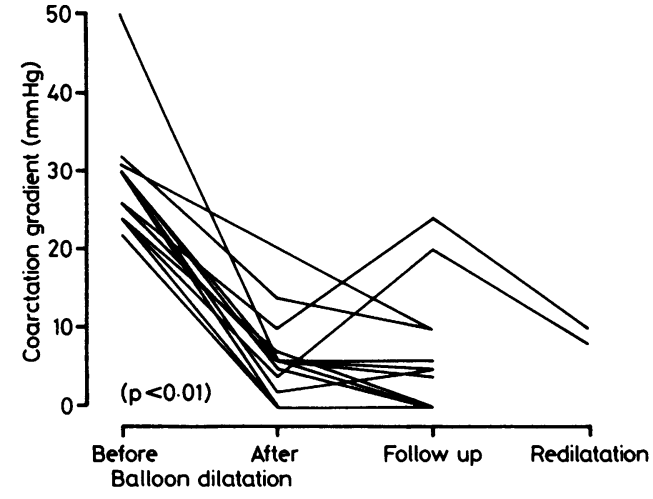

Fig 1 Systolic pressure gradient across the coarctation before and after balloon dilatation, at the one year follow up catheterisation, and after repeat dilatation (two patients). Two pairs of patients had identical results.

$18 \mathrm{~mm}$ in diameter. The ratio of the balloon diameter to coarctation diameter was between 2 and 2.5 in all but five patients (table).

Immediately after balloon inflation the pressure gradient across the site of coarctation was reduced to 0-20 mm Hg (mean $5.7 \mathrm{~mm} \mathrm{Hg}$; $<0.01$ ). On repeat angiography the diameter of the coarctation had increased significantly to $7-20 \mathrm{~mm}$ (mean $11.8 \mathrm{~mm}$; $\mathrm{p}<0.01$ ). In patient 2 a fusiform aneurysm of the coarctation site was produced (fig 3 ). The ratio of the balloon to coarctation diameter in this patient was 3.8.

After the dilatation few vascular problems were seen. In particular, there were no embolic complications and post-dilatation hypertension did not occur. The right femoral artery pulse was weak in only one patient at one year. The clinical signs of coarctation resolved in all patients and no patient be-

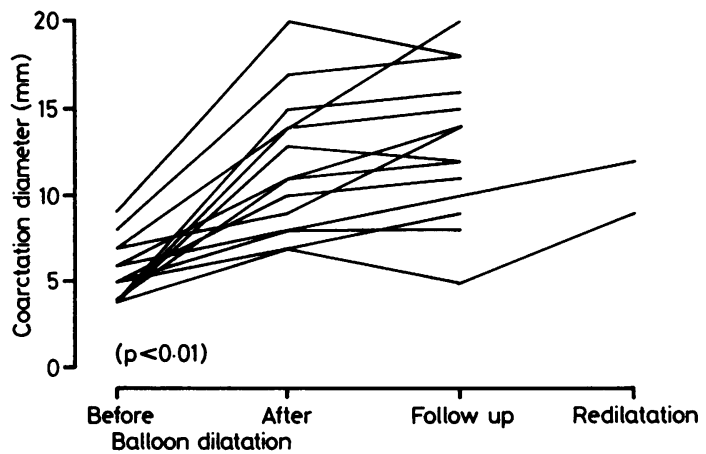

Fig 2 Diameter of the aorta at the coarctation before and after balloon dilatation, at the one year follow up catheterisation, and after repeat dilatation (two patients). Two patients had identical results.

came hypertensive after the atenolol was withdrawn. One patient had systolic hypertension and all others were normotensive at the time of their repeat cardiac catheterisation.

At recatheterisation the residual coarctation gradient was between 0 and $24 \mathrm{~mm} \mathrm{Hg}$ (mean $5.6 \mathrm{~mm}$ $\mathrm{Hg}$ ). In 11 patients the residual gradient was $\leqslant 10$ $\mathrm{mm} \mathrm{Hg}$ and the angiographic appearances were satisfactory with no sign of aortic dilatation or aneurysm (fig 4). Two patients had developed haemodynamic and angiographic evidence of restenosis and underwent successful repeat dilatation. There was a small discrete aneurysm at the coarctation site in patient 1 (fig 5) in whom the balloon to coarctation diameter ratio was 4.5 . There had been no change in the angiographic appearance of the fusiform aneurysm in patient 2 (fig 3 ). No patient has subsequently required operation. Long term follow up of all patients is continuing.

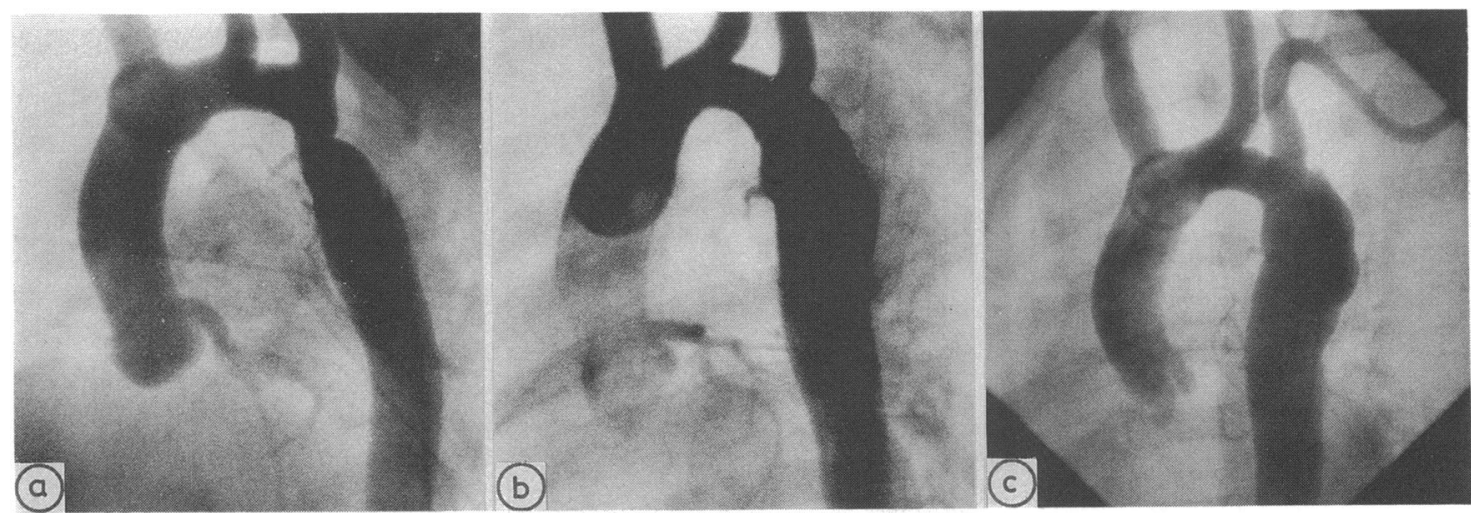

Fig 3 Aortic angiogram in patient 2 before $(a)$ and after (b) dilatation and at one year follow up (c). Note the fusiform aneurysm of the aorta at the site of coarctation immediately after dilatation (b). There was no significant change over the following year (c). Balloon:coarctation ratio $3 \cdot 8$. 


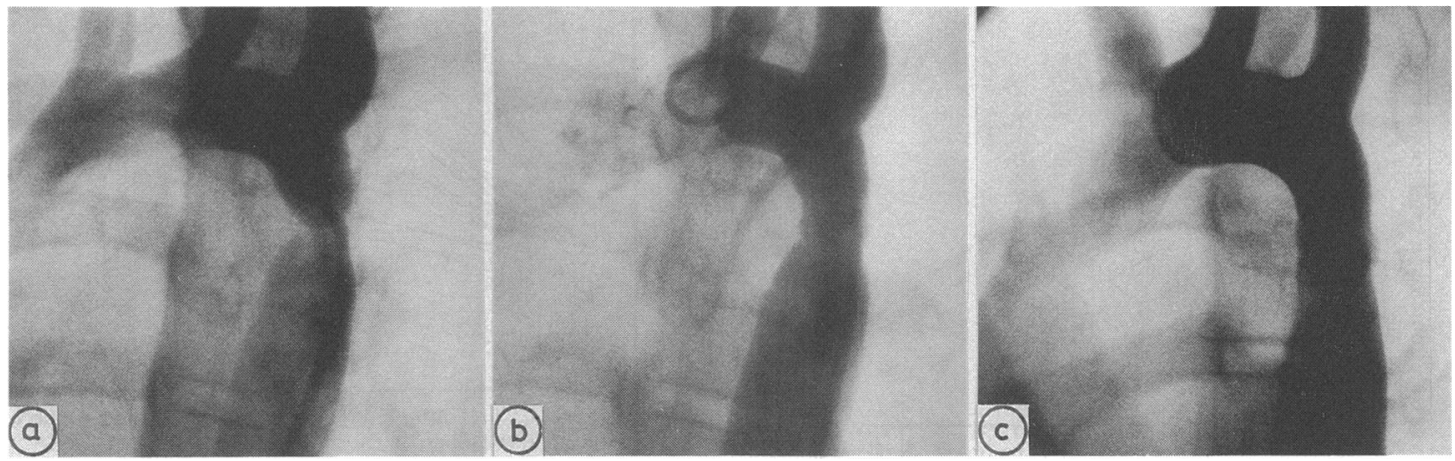

Fig 4 Arch aortogram in patient 9, demonstrating successful balloon dilatation which has been maintained at one year. Balloon:coarctation ratio $2 \cdot 4$.

\section{Discussion}

Although the immediate results of operative treatment of coarctation of the aorta are good, it carries a small but significant morbidity. Late mortality is usually related to cardiovascular problems, particularly residual hypertension. Restenosis or aneurysm may develop, the latter particularly after patch aortoplasty. ${ }^{11} 12$ Even selected normotensive patients with good operative results have abnormalities such as residual left ventricular hypertrophy and hyperkinesia. ${ }^{1}$ Hypertension may occur on exercise, even if there is no residual coarctation, and is probably related to abnormal vascular tone in the upper half of the body.

Because balloon angioplasty achieves its effect by disruption of the intima and media of the aortic wall, there is concern over the possibility of aneurysm formation. ${ }^{91013}$ Balloon angioplasty has been pro- posed as the treatment of choice for restenosis of coarctation because the risk of late aneurysm formation is probably less than the problems associated with repeat operation. ${ }^{5}$ If long term follow up shows a low incidence of aneurysm and other problems, balloon angioplasty may also be preferred to surgical resection of unoperated coarctation.

There are few reports of the development of aneurysms after balloon dilatation of native coarctation. ${ }^{310}$ Cooper et al found aneurysms in three $(43 \%)$ of seven children after the use of balloons 1 $\mathrm{mm}$ smaller than the diameter of the aorta proximal to the coarctation. ${ }^{3}$ They did not compare balloon diameter with coarctation diameter. Marvin et al reported that six $(55 \%)$ of eleven children developed aortic aneurysms after 7-14 months. ${ }^{10}$ In these patients the balloons used for dilatation were 2.5-3 times larger than the diameter of the coarctation determined angiographically. All six aneurysms were
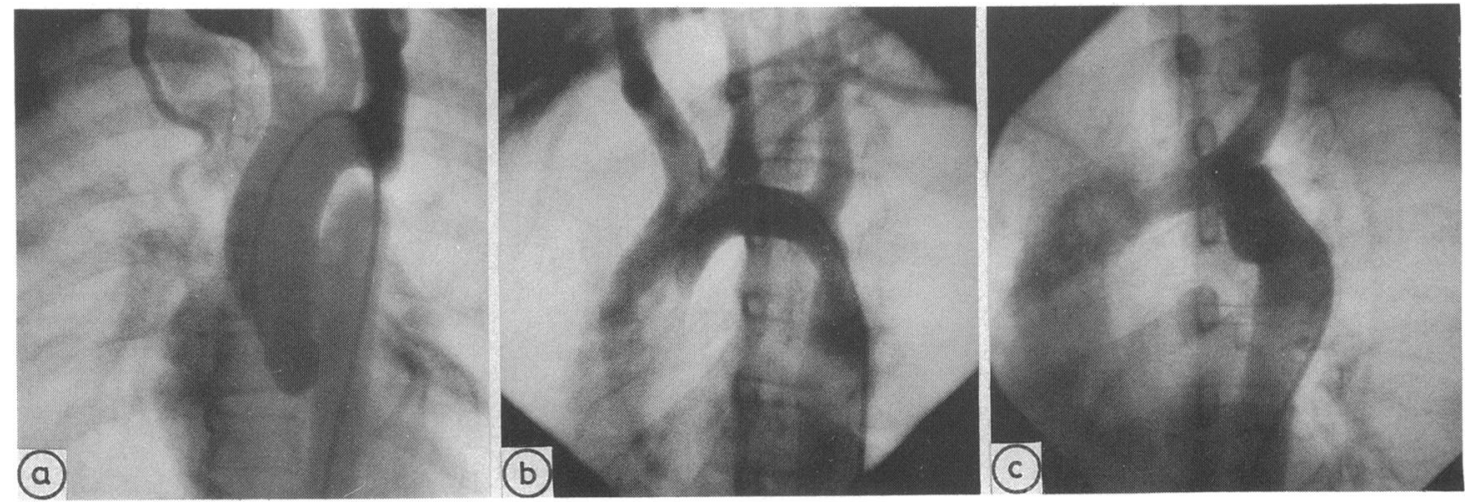

Fig 5 Aortic angiogram in patient 1 before (a) and after (b) balloon dilatation. Repeat angiogram at one year (c) shows a small saccular aneurysm at the coarctation site. Balloon:coarctation ratio 4.5. Frame (a) is the anteroposterior projection while (b) and (c) are left anterior oblique views. 
resected at operation because of the angiographic appearances. Our results do not confirm this high incidence of early aneurysm development, and neither fusiform nor saccular aneurysm formation was seen in any patient with a balloon to coarctation ratio $<3.8$.

Various technical aspects of the procedure may influence its efficacy and also the risk of late complications. They will be assessed only by longer follow up of greater numbers of patients. Larger balloons may produce better relief of coarctation at the expense of a higher incidence of late aneurysm. The only aneurysm we found at follow up angiography (fig 5) occurred in the patient with the highest balloon to coarctation ratio. The rate of balloon inflation, the number of inflations, the maximum pressure achieved, and the duration of inflation may also affect immediate and long term results but no data are available to confirm this. Since measurement of the aortic diameter from the video monitor is inaccurate, we now correct for magnification by using a calibrated marker catheter. It may be that the diameter of the coarctation is a better guide to the selection of balloon size than the aortic diameter but the coarctation is difficult to measure accurately. Although the balloon size necessary for relief of pulmonary valve stenosis can, in our experience, be predicted from the body weight or body surface area, no such relation exists in patients with coarctation.

Balloon dilatation of aortic coarctation is effective in relieving the obstruction and associated systemic hypertension. Our results suggest that the frequency of aneurysm development at early reassessment is much less than has been reported previously and that aneurysm development may be avoidable. These early results are encouraging but long term follow up will be necessary before balloon angioplasty can be confirmed as a safe and effective alternative to surgical resection for the primary relief of aortic coarctation.

\section{References}

1 Carpenter MA, Dammann JF, Watson DD, Jedeikin R, Tompkins DG, Better GA. Left ventricular hyperkinesia at rest and during exercise in normotensive patients 2 to 27 years after coarctation repair. $\mathrm{J} \mathrm{Am}$ Coll Cardiol 1985;6:879-88.

2 Lababidi ZA, Daskalopoulos DA, Stoeckle H Jr. Transluminal balloon angioplasty: experience with 27 patients. Am J Cardiol 1984;54:1288-91.

3 Cooper RS, Ritter SB, Rothe WB, Chen CK, Griepp R, Golinko RJ. Angioplasty for coarctation of the aorta: long-term results. Circulation 1987;75:600-4.

4 Lock JE, Bass JL, Amplatz K, Fuhrman BP, Castaneda-Zuniga $\mathrm{W}$. Balloon dilation angioplasty of aortic coarctation in infants and children. Circulation 1983;68:109-16.

5 Lock JE, Keane JF, Fellows KE. The use of catheter intervention procedures for congenital heart disease. J Am Coll Cardiol 1986;7:1420-3.

6 Finley JP, Beaulieu RG, Nanton MA, Roy DL. Balloon catheter dilatation of coarctation of the aorta in young infants. Br Heart $J$ 1983;50:411-5.

7 Lock JE, Niemi T, Burke BA, Einzig S, CastanedaZuniga WR. Transcutaneous angioplasty of experimental coarctation. Circulation 1982;66:1280-6.

8 Lock JE, Castaneda-Zuniga WR, Bass JL, Foker JE, Amplatz K, Anderson RW. Balloon dilatation of excised aortic coarctations. Radiology 1982;143:689-91.

9 Bull C. Interventional catheterisation in infants and children. Br Heart J 1986;56:197-200.

10 Marvin WJ, Mahoney LT, Rose EF. Pathological sequelae of balloon dilatation angioplasty for unoperated coarctation of the aorta in children [Abstract]. J Am Coll Cardiol 1986;7:117A.

11 Ala-Kulju K, Jarvinen A, Maamies T, Mattila S, Merikallio E. Late aneurysms after patch aortoplasty for coarctation of the aorta in adults. Thorac Cardiovasc Surg 1983;31:301-5.

12 Hehrlein FW, Mulch J, Rautenburg HW, Schlepper $\mathrm{M}$, Scheld $\mathrm{HH}$. Incidence and pathogenesis of late aneurysms after patch graft aortoplasty for coarctation. J Thorac Cardiovasc Surg 1986;92:226-30.

13 Lock JE. Now that we can dilate, should we? $A m \mathrm{~J}$ Cardiol 1984;54:1360. 